\title{
O sonho como palavra precisa
} Fernando Scheibe*

\section{Resumo:}

Apresentação da versão brasileira de "L'action restreinte", uma das Divagations de Stéphane Mallarmé, que a Editora da UFSC acaba de publicar. "Livro e nãolivro" realizado no decorrer de trinta anos, a íntegra dos fragmentos em prosa poética do poeta francês aparecem pela primeira vez no Brasil pelas mãos de Fernando Scheibe, professor de literatura da UFAM e tradutor da revista Acéphale.

\section{Palavras-chave:}

Poesia; prosa; livro; Mallarmé

Stéphane - Étienne de batismo - Mallarmé (1842 - 1898), esse "pequeno professor de inglês", gestou, quase em silêncio, uma das obras mais radicais da literatura moderna. Muitos a consideram um verdadeiro divisor de águas. 0 Foucault dos anos 60, por exemplo, vê em Mallarmé o marco inicial da "literatura propriamente dita".

Mais conhecido como o poeta de "Um lance de dados" e de poemas como "Brinde", "Soneto em ' $y x^{\prime \prime}$ ou "O virgem, o vivaz e o belo hoje", Mallarmé foi também um prosador exquis, embora essa categoria, a prosa, seja de existência duvidosa em seu universo. Como se lê em Crise de verso, "[Victor Hugo fez-se] a divindade assim de uma majestosa ideia inconsciente, a saber, que a forma chamada verso é simplesmente ela mesma a literatura; que verso há tão logo se acentua a dicção, ritmo desde que estilo".

Publicado em 1897, pouco tempo antes da morte do poeta, Divagações reúne textos "em prosa" escritos por Mallarmé ao longo de toda sua vida. Como o indica seu título e sua ambivalente apresentação, Divagações é e não é um livro, tem e não tem uma arché, uma arquitetura. Embora sejam uma grande bricolagem, um grande pasearse aqui e acolá ao longo de mais de trinta anos, "as Divagações aparentes tratam um tema, de pensamento, único". Qual? as possibilidades políticas da poesia.

\footnotetext{
* Tradutor e professor de teoria da literatura na Universidade Federal do Amazonas (UFAM).
} 
O texto que segue, "A ação restrita", forma junto com mais dois, "À venda" e "O livro, instrumento espiritual", uma das diversas seções das Divagações, nomeada "Quanto ao livro". Trata-se na verdade da reescrita de um dos artigos da série Variations sur un sujet que acolhe, com audácia, apesar do desarranjo, primeiro, causado pela disposição tipográfica, a amical, a todos pronta Revue Blanche".

Nesta seção, questiona-se o papel do livro na cidade, sua potência e sua impotência. O poeta, aquele que escolhe o caminho mais difícil, arrancar a linguagem à "universal reportagem" está condenado a uma ação restrita, mas que não se confunde com a simples desistência do político.

A leitura das Divagações deixa bem claro isto: o poeta não é simplesmente aquele que persegue isoladamente sua obra alquímico-verbal; ele não fica alheio aos acontecimentos (escândalo no Panamá, atentados anarquistas, krach na venda de livros, a última peça levada no Éden...), antes os alheia a seu significado corrente anotando-os "sob a luz própria ao sonho".

$\mathrm{E}$ aqui vale a pena acompanhar Jaques Rancière que, em seu belo Mallarmé, La politique de la sirène, nos adverte de que, nesse escritor, sonho, assim como mistério, não remete a algo de vago. Pelo contrário, "é uma palavra precisa":

O sonho é a potência de surpreender pelo olhar e de marcar pela palavra esse outro espetáculo, "claro, mais que os palcos vasto". Ele é o ponto de vista que elege um "aspecto". Ou antes, é o aspecto que é "ponto de vista": ponto a partir do qual, como o diz um outro poema reputado incompreensível, se define um lugar carregado de "vista" em lugar de "visões" (...) A poesia é perseguição desta verdade, desta exata interrupção.

A política da sereia está na maneira de olhar e de escrever. Escreve-se, não apenas com palavras, mas também com os brancos. Nesse sentido é também importante ler esta e as demais Divagações à luz das considerações feitas pelo próprio Mallarmé a respeito do "desarranjo tipográfico" de seus textos:

Razão dos intervalos, ou brancos - que o longo artigo ordinário de revista, ou enchimento, indica, forçosamente, ao olho que as distingue por lugares, entretanto, algumas escamas de interesse: por que não o restringir a esses fragmentos obrigatórios onde cintilou o tema, depois simplesmente substituir, pela ingenuidade do papel, as transições, quaisquer? Uma publicação, viva, no sumário marcando o meio, exato, entre artigos encurtados de jornal e a massa ociosa em que flutua muito periódico, exige a maneira. As quebras do texto, todos se tranquilizarão, observam de concordar, com sentido e não inscrevem espaço nu senão até seus pontos de iluminação: uma forma, 
talvez, daí saia, atual, permitindo, ao que foi longo tempo o poema em prosa e nossa pesquisa, culminar, enquanto, se juntamos melhor as palavras, poema crítico. Mobilizar, ao redor de uma ideia, as luminosidades diversas do espírito, à distância desejada, por frases: ou como, verdadeiramente, esses moldes da sintaxe mesmo alargada, um muito pequeno número os resume, cada frase, a se destacar em parágrafo ganha por isolar um tipo raro com mais liberdade que no carreto por uma corrente de volubilidade. Mil exigências, muito singulares, aparecem ao uso nesse tratamento do escrito, que percebo pouco a pouco: sem dúvida há meio, aí, para um poeta que por hábito não pratica o verso livre, de mostrar, no aspecto de trechos compreensivos e breves, na sequência, com experiência, tais ritmos imediatos de pensamento ordenando uma prosódia.

É evidente que aí se anunciava também a explosão sintática de "Um lance de dados".

A presente tradução faz parte de uma tradução integral das Divagações recémpublicada pela Editora da UFSC e foi feita com base na recente edição das obras completas de Mallarmé, organizada por Bertrand Marchal e publicada na coleção Pléiade da Editora Gallimard (o volume 2, que inclui as Divagações, saiu em 2003), sob supervisão do Professor Joaquim Brasil Fontes, como parte de um pós-doutoramento junto à Faculdade de Educação da UNICAMP com financiamento da Fapesp, à qual fica aqui meu agradecimento.

\section{Title:}

The dream as a precise word

\section{Abstract:}

Presentation of the Brazilian version of "L'action restreinte," one of the Divagations by Stéphane Mallarmé, which has been just published by Editora da UFSC. "Book and not-book" written along thirty years, the complete fragments in poetic prose by the French poet appear for the first time in Brazil by the hands of Fernando Sheibe, professor of literature at UFAM and translator for the journal Acéphale by Bataille.

\section{Keywords:}

Poetry, prose, book, Mallarmé 


\section{A ação restrita* Stéphane Mallarmé}

Várias vezes veio um Camarada, o mesmo, esse outro, confiar-me a necessidade de agir: que visava ele - como a expedição em minha direção anunciou de sua parte, também, a ele jovem, a ocupação de criar, que parece suprema e dar certo com palavras; insisto, que intentava ele expressamente?

Distender os punhos, em ruptura de sonho sedentário, para um tripudiante face a face com a ideia, assim como uma vontade toma ou se mexer: mas a geração parece pouco agitada, além do desinteresse político, pela inquietação de extravagar do corpo. Excetuada a monotonia, certamente, de enrolar, entre os jarretes, sobre a calçada, segundo o instrumento em alta, a ficção de um deslumbrante trilho contínuo.

Agir, sem isto e para quem não faz começar o exercício em fumar, significou, visitante, compreendo você, filosoficamente, produzir sobre muitos um movimento que lhe dê em retorno a comoção de que você foi dele o princípio, logo você existe: do que ninguém se crê, previamente, seguro. Esta prática compreende dois modos; ou, por uma vontade, à revelia, que dura uma vida, até à explosão múltipla - pensar, isto: senão, os escoadouros ao alcance agora numa previdência, jornais e seu turbilhão, aí determinar uma força num sentido, qualquer por diversos contrariada, com a imunidade do resultado nulo.

A gosto, segundo a disposição, plenitude, pressa.

Seu ato sempre se aplica a papel; pois meditar, sem traços, torna-se evanescente, nem que se exalte o instinto em algum gesto veemente e perdido que você buscou.

\section{Escrever -}

\footnotetext{
* O presente texto corresponde à tradução de "L'action restreinte", uma das Divagations de Mallarmé em tradução de Fernando Scheibe: Divagações. Florianópolis: Editora UFSC, 2010.
} 
O tinteiro, cristal como uma consciência, com sua gota, no fundo, de trevas relativa a que alguma coisa seja: depois, afasta a lâmpada.

Você notou, não se escreve, luminosamente, sobre campo obscuro, o alfabeto dos astros, só ele, assim se indica, esboçado ou interrompido; o homem prossegue preto sobre branco.

Essa dobra de sombria renda, que retém o infinito, tecida por mil, cada um segundo o fio ou prolongamento ignorado seu segredo, reúne entrelaços distantes onde dorme um luxo a inventariar, estrige, nó, folhagens e apresentar.

Com o nada de mistério, indispensável, que permanece, exprimido, algum pouco.

Não sei se o Hóspede perspicazmente circunscreve seu domínio de esforço: será de meu agrado marcá-lo, também certas condições. O direito a algo realizar de excepcional ou que falte às manobras vulgares, se paga, em qualquer um, pela omissão de si e dir-se-ia pela sua morte como um tal. Façanhas, ele as comete no sonho, para não incomodar ninguém; mas, ainda, o programa permanece afixado para aqueles que não se importam.

O escritor, de seus males, dragões que ele mimou, ou de uma alegria, deve se instituir, no texto, o espiritual histrião.

Tablado, lustre, obnubilação dos tecidos e liquefação de espelhos, na ordem real, até os saltos excessivos de nossa forma velada em torno de uma sentença, de pé, da viril estatura, um Lugar se apresenta, cena, majoração diante de todos do espetáculo de Si; aí, em razão dos intermediários da luz, da carne e dos risos, o sacrifício que the faz, relativamente a sua personalidade, o inspirador, resulta completo ou é, numa ressurreição estranha, terminado por este aqui: de quem o verbo repercutido e vão doravante se exala pela quimera orquestral.

Uma sala, ele se celebra, anônimo, no herói. 
Tudo, como funcionamento de festas: um povo testemunha de sua transfiguração em verdade.

Honra.

Procurem, onde há, alguma coisa de semelhante -

Será ele reconhecido nesses imóveis suspeitos destacando-se, por uma sobrecarga no banal, do comum alinhamento, com pretensão a sintetizar os fatos diversos de um bairro; ou, se algum frontão, segundo o gosto divinatório francês, isola, sobre uma praça, seu espectro, eu saúdo. Indiferente a que, aqui e lá, verta-se como ao longo de tubos, a chama de línguas reduzidas.

Assim a Ação, no modo em que se conveio, literário, não transgride o Teatro; limita-se a ele, à representação - imediato esvanecimento do escrito. Termine, na rua, outra parte, isso, a máscara cai, não tenho a fazer com o poeta: perjure seu verso, ele não é dotado mais que de fraco poder por fora, você preferiu alimentar o saldo de intrigas cometidas ao indivíduo. De que serve precisar-lhe, criança sabendo-o, como eu, que dele só conservei noção por uma qualidade ou um defeito de infância exclusivos, esse ponto, que tudo, veículo ou colocação, agora oferecido ao ideal, Ihe é contrário - quase uma especulação, sobre seu pudor, pelo seu silêncio - ou defeituoso, não direto e legítimo no sentido que agora mesmo quis um impulso e viciado. Como jamais mal-estar basta, esclarecerei, seguramente, com digressões próximas no número que será preciso, essa recíproca contaminação da obra e dos meios: mas anteriormente não conveio ele espaçosamente em se exprimir, assim como um cigarro, por jogos circunvolutórios, cujo vago, pelo menos, se traçasse sobre a luz elétrica e crua?

Um delicado, espero-o, padeceu -

Exteriormente, como o grito da extensão, o viajante percebe a aflição do apito. "Sem dúvida" ele se convence: "atravessamos um túnel - a época - aquele, longo o derradeiro, arrastando-se sob a cidade antes da estação todo-poderosa do virginal palácio central, que coroa." O subterrâneo durará, ó impaciente, seu 
recolhimento para preparar o edifício de alto vidro enxugado por um voo/furto da Justiça.

O suicídio ou abstenção, nada fazer, por quê? - Única vez no mundo, porque em razão de um acontecimento sempre que explicarei, não há Presente, não - um presente não existe. Por falta de que se declare a Massa, por falta - de tudo. Mal informado aquele que se gritaria seu próprio contemporâneo, desertando, usurpando, com impudência igual, quando o passado cessou e que tarda um futuro ou que os dois se remesclam perplexamente em vista de mascarar o afastamento. Fora dos premier-Paris encarregados de divulgar uma vez no quotidiano nada e imperitos se o flagelo mede seu período por um fragmento, importante ou não, de século.

Assim guarde-se e esteja aí.

A poesia, sagra(ção); que tenta, em castas crises isoladamente, durante a outra gestação em curso.

Publique.

O Livro, onde vive o espírito satisfeito, em caso de mal-entendido, um obrigado por alguma pureza de folguedo a sacudir o grosso do momento. Despersonificado, o volume, tanto quanto a gente se separa dele como autor, não reclama aproximação de leitor. Tal, saiba, entre os acessórios humanos, ele tem lugar totalmente só: feito, sendo. O sentido sepultado se move e dispõe, em coro, das folhas.

Longe, a soberba de colocar em interdito, mesmo quanto aos faustos, o instante: constata-se que um acaso aí denega os materiais de confrontação a alguns sonhos; ou ajuda uma atitude especial. 
Você, Amigo, que não deve ser frustrado de anos porque paralelos ao surdo labor geral, o caso é estranho: peço-lhe, sem julgamento, por falta de considerantes súbitos, que você trate minha indicação como uma loucura não o proíbo, rara. Entretanto tempera-a já essa sabedoria, ou discernimento, se não vale mais - arriscar sobre um estado no mínimo incompleto circundante, certas conclusões de arte extremas que podem explodir, diamantariamente, nesse tempo para sempre, na integridade do Livro - jogá-las, mas e por uma triunfal inversão, com a injunção tácita que nada, palpitando no flanco insciente da hora, nas páginas mostrado, claro, evidente, a encontre pronta: ainda que não seja talvez uma outra em que deva iluminar. 


\section{L'action restreinte}

Stéphane Mallarmé

Plusieurs fois vint un Camarade, le même, cet autre, me confier le besoin d'agir : que visait-il - comme la démarche à mon endroit annonça de sa part, aussi, à lui jeune, l'occupation de créer, qui paraît suprême et réussir avec des mots ; j'insiste, qu'entendait-il expressément ?

Se détendre les poings, en rupture de songe sédentaire, pour un trépignant visà-vis avec l'idée, ainsi qu'une envie prend ou bouger : mais la génération semble peu agitée, outre le désintéressement politique, du souci d'extravaguer du corps. Excepté la monotonie, certes, d'enrouler, entre les jarrets, sur la chaussée, selon l'instrument en faveur, la fiction d'un éblouissant rail continu.

Agir, sans ceci et pour qui n'en fait commencer l'exercice à fumer, signifia, visiteur, je te comprends, philosophiquement, produire sur beaucoup un mouvement qui te donne en retour l'émoi que tu en fus le principe, donc existes : dont aucun ne se croit, au préalable, sûr. Cette pratique entend deux façons ; ou, par une volonté, à l'insu, qui dure une vie, jusqu'à l'éclat multiple penser, cela : sinon, les déversoirs à portée maintenant dans une prévoyance, journaux et leur tourbillon, y déterminer une force en un sens, quelconque de divers contrariée, avec l'immunité du résultat nul.

Au gré, selon la disposition, plénitude, hâte.

Ton acte toujours s'applique à du papier ; car méditer, sans traces, devient évanescent, ni que s'exalte l'instinct en quelque geste véhément et perdu que tu cherchas. 
Écrire -

L'encrier, cristal comme une conscience, avec sa goutte, au fond, de ténèbres relative à ce que quelque chose soit : puis, écarte la lampe.

Tu remarquas, on n'écrit pas, lumineusement, sur champ obscur, l'alphabet des astres, seul, ainsi s'indique, ébauché ou interrompu ; I'homme poursuit noir sur blanc.

Ce pli de sombre dentelle, qui retient l'infini, tissé par mille, chacun selon le fil ou prolongement ignoré son secret, assemble des entrelacs distants où dort un luxe à inventorier, stryge, nœud, feuillages et présenter.

Avec le rien de mystère, indispensable, qui demeure, exprimé, quelque peu.

Je ne sais pas si I'Hôte perspicacement circonscrit son domaine d'effort : ce me plaira de le marquer, aussi certaines conditions. Le droit à rien accomplir d'exceptionnel ou manquant aux agissements vulgaires, se paie, chez quiconque, de l'omission de lui et on dirait de sa mort comme un tel. Exploits, il les commet dans le rêve, pour ne gêner personne ; mais encore, le programme en reste-t-il affiché à ceux qui n'ont cure.

L'écrivain, de ses maux, dragons qu'il a choyés, ou d'une allégresse, doit s'instituer, au texte, le spirituel histrion.

Plancher, lustre, obnubilation des tissus et liquéfaction de miroirs, en I'ordre réel, jusqu'aux bonds excessifs de notre forme gazée autour d'un arrêt, sur pied, de la virile stature, un Lieu se présente, scène, majoration devant tous du spectacle de Soi ; là, en raison des intermédiaires de la lumière, de la chair et des rires le sacrifice qu'y fait, relativement à sa personnalité, l'inspirateur, aboutit complet ou c'est, dans une résurrection étrangère, fini de celui-ci : de qui le verbe répercuté et vain désormais s'exhale par la chimère orchestrale.

Une salle, il se célèbre, anonyme, dans le héros.

Tout, comme fonctionnement de fêtes : un peuple témoigne de sa transfiguration en vérité. 
Honneur.

Cherchez, où c'est, quelque chose de pareil -

Le reconnaîtra-t-on dans ces immeubles suspects se détachant, par une surcharge en le banal, du commun alignement, avec prétention à synthétiser les faits divers d'un quartier ; ou, si quelque fronton, d'après le goût divinatoire français, isole, sur une place, son spectre, je salue. Indifférent à ce qui, ici et là, se débite comme le long de tuyaux, la flamme aux langues réduites.

Ainsi l'Action, en le mode convenu, littéraire, ne transgresse pas le Théâtre ; s'y limite, à la représentation - immédiat évanouissement de l'écrit. Finisse, dans la rue, autre part, cela, le masque choit, je n'ai pas à faire au poëte : parjure ton vers, il n'est doué que de faible pouvoir dehors, tu préféras alimenter le reliquat d'intrigues commises à l'individu. À quoi sert de te préciser, enfant le sachant, comme moi, qui n'en conservai notion que par une qualité ou un défaut d'enfance exclusifs, ce point, que tout, véhicule ou placement, maintenant offert à l'idéal, y est contraire - presque une spéculation, sur ta pudeur, pour ton silence - ou défectueux, pas direct et légitime dans le sens que tout à l'heure voulut un élan et vicié. Comme jamais malaise ne suffit, j'éclairerai, assurément, de digressions prochaines en le nombre qu'il faudra, cette réciproque contamination de l'œuvre et des moyens : mais auparavant ne convint-il spacieusement de s'exprimer, ainsi que d'un cigare, par jeux circonvolutoires, dont le vague, à tout le moins, se traçât sur le jour électrique et cru ?

Un délicat a, je l'espère, pâti —

Extérieurement, comme le cri de l'étendue, le voyageur perçoit la détresse du sifflet. «Sans doute » il se convainc : « on traverse un tunnel - l'époque celui, long le dernier, rampant sous la cité avant la gare toute puissante du virginal palais central, qui couronne. » Le souterrain durera, ô impatient, ton recueillement à préparer l'édifice de haut verre essuyé d'un vol de la Justice. 
Le suicide ou abstention, ne rien faire, pourquoi ? - Unique fois au monde, parce qu'en raison d'un événement toujours que j'expliquerai, il n'est pas de Présent, non - un présent n'existe pas... Faute que se déclare la Foule, faute de tout. Mal informé celui qui se crierait son propre contemporain, désertant, usurpant, avec impudence égale, quand du passé cessa et que tarde un futur ou que les deux se remêlent perplexement en vue de masquer l'écart. Hors des premierParis chargés de divulguer une foi en le quotidien néant et inexperts si le fléau mesure sa période à un fragment, important ou pas, de siècle.

Aussi garde-toi et sois là.

La poésie, sacre ; qui essaie, en de chastes crises isolément, pendant l'autre gestation en train.

Publie.

Le Livre, où vit l'esprit satisfait, en cas de malentendu, un obligé par quelque pureté d'ébat à secouer le gros du moment. Impersonnifié, le volume, autant qu'on s'en sépare comme auteur, ne réclame approche de lecteur. Tel, sache, entre les accessoires humains, il a lieu tout seul : fait, étant. Le sens enseveli se meut et dispose, en chœur, des feuillets.

Loin, la superbe de mettre en interdit, même quant aux fastes, l'instant : on constate qu'un hasard y dénie les matériaux de confrontation à quelques rêves ; ou aide une attitude spéciale.

Toi, Ami, qu'il ne faut frustrer d'années à cause que parallèles au sourd labeur général, le cas est étrange : je te demande, sans jugement, par manque de considérants soudains, que tu traites mon indication comme une folie je ne le défends, rare. Cependant la tempère déjà cette sagesse, ou discernement, s'il ne vaut pas mieux - que de risquer sur un état à tout le moins incomplet environnant, certaines conclusions d'art extrêmes qui peuvent éclater, diamantairement, dans ce temps à jamais, en l'intégrité du Livre - les jouer, 
mais et par un triomphal renversement, avec l'injonction tacite que rien, pal pitant en le flanc inscient de l'heure, aux pages montré, clair, évident, ne la trouve prête ; encore que n'en soit peut-être une autre où ce doive illuminer. 
